\title{
IMPLICAÇÃO DA EXPLORAÇÃO DOS DESENHOS INDUSTRIAIS NO UNIVERSO DA CONCORRÊNCIA.
}

\begin{abstract}
Almir Garcia Fernandes ${ }^{1}$
\section{RESUMO}

O direito de exploração conferido aos desenhos industriais constitui instrumento eficaz no combate a concorrência desleal, pois protege o empresário das práticas de concorrência desleal, em especial na imitação do formato de produtos e embalagens. Este estudo tem por finalidade analisar essa exploração econômica, mensurando se os desenhos industrias podem ser utilizados de forma abusiva por seus titulares. Pretende-se demonstrar que essa proteção acaba por gerar destacar os produtos de uma determinada empresa, no sentido fidelizar consumidores em detrimento de concorrentes. O método de pesquisa será o indutivo e os procedimentos metodológicos serão o estudo dogmático jurídico e sistemático.
\end{abstract}

Palavras - Chave: Desenho industrial; exploração econômica; concorrência; licenciamento; consumidor.

\section{IMPLICATION OF THE EXPLORATION OF DESIGN IN THE COMPETITION UNIVERSE.}

\begin{abstract}
The exploitation right conferred on designs is an effective instrument in the fight against unfair competition, as it protects the trader from unfair practices, especially in imitation of the format of products and packaging. This study aims to analyze this economic exploitation, measuring whether designs can be misused by their owners. It is intended to demonstrate that this protection ends up generating the highlight of the products, in the sense of loyal consumers to the detriment of competitors. The research method will be the inductive and the methodological procedures will be the legal and systematic dogmatic study.
\end{abstract}

Key words: Design; economic exploitation; competition; licensing; consumer.

\section{INTRODUÇÃO.}

Os direitos da Propriedade Industrial têm origens históricas relacionadas a exploração de bens incorpóreos que oferecem aos seus titulares uma proteção jurídica (titularidade) e uma proteção econômica (exclusividade), com a intenção de beneficiar

\footnotetext{
${ }^{1}$ Doutor em Direito Comercial pela PUC de São Paulo. Mestre em Direito das Relações EconômicoEmpresariais pela Universidade de Franca. Professor de Direito Empresarial no Centro Universitário do Planalto de Araxá. E-mail: almirgarcia@ uniaraxa.edu.br
} 
economicamente seu titular de tecnologias e elementos de diferenciação dentre seus concorrentes, oferecendo-lhe elementos para excluir terceiros não autorizados. ${ }^{2}$

Nasceu em virtude da própria garantia da concorrência, pois oferece elementos diferenciadores aos produtos postos à disposição da clientela (marcas, indicações geográficas e desenho industrial) ou na exploração de determinadas tecnologias (patentes de invenção ou modelo de utilidade).

Há, portanto, uma ampla gama de bens incorpóreos que aproximam a clientela do empresário e esses bens atualmente são considerados como insumos que diferenciam o empresário de seus concorrentes, proporcionando-lhes sucesso no desempenho de sua atividade econômica.

Copetti (2007, p.203) destaca inclusive que "a riqueza e o poder de um país se medem não mais por fatores de ordem puramente material, mas pela determinação de conhecimento tecnológico. A sociedade que seria chamada de pós-industrial é hoje a sociedade do conhecimento".

Nesse sentido é importante destacar a importância desses bens incorpóreos e a implicação de sua exploração no universo da concorrência, a fim de identificar situações em que a sua utilização possa causar prejuízos ao mercado, gerando uma tendência contrária à proteção que lhes fora conferida.

Entretanto, é importante delimitar o enfoque deste presente estudo, uma vez que não é possível tratar de todos os bens de proteção da propriedade industrial neste artigo. Assim, o objetivo desta análise limitar-se-á aos desenhos industriais, a sua exploração e as implicações desta exploração no universo da concorrência.

A exploração dos desenhos industriais está intimamente relacionada com os aspectos estéticos que os produtos são apresentados para os consumidores, sendo inclusive essa a função esperada pelo seu titular, ou seja, a de "dotar a mercadoria produzida de um elemento ornamental (nela mesma ou na embalagem) que a individualize no mercado, em relação aos concorrentes" (COELHO, 2012, p. 210).

\footnotetext{
${ }^{2}$ Bruno Falcone destaca a predominância da Propriedade Industrial sobre o Direito da Concorrência no início do século XIX: (...) o direito da concorrência pouco fazia no sentido de alterar o limitar a prevalência dos direitos de propriedade industrial, permitindo-se inclusive a imposição, por parte do titular da patente, de compra de produto não patenteado como condição para a venda do produto protegido, prática conhecida naquele ordenamento como tryng arrangements. Permitia-se, portanto, a prática de uma conduta que atualmente seria considerada duplamente ilícita do ponto de vista do direito antitruste: a chamada 'venda casada' e a evidente extrapolação do escopo de direito de propriedade industrial protegido. (2013, p. 40).
} 
Tal como ocorre com todos os bens da Propriedade Industrial, a exploração exclusiva conferida aos desenhos industriais constitui instrumento eficaz no combate a concorrência desleal, pois protege o empresário das práticas anticompetivivas de seus concorrentes, especialmente no que diz respeito a possibilidade de imitação do formado dos produtos que comercializa ou mesmo de suas embalagens.

Este estudo tem por finalidade analisar a exploração econômica dos desenhos industriais, seja para a proteção de bens oferecidos aos consumidores ou como método de diferenciação de concorrentes. Da mesma forma é indispensável analisar se os desenhos industrias podem ser utilizados de forma abusiva por seus titulares, bem como se estes seriam obrigados a licenciar concorrentes. Por fim, pretende-se demonstrar ao final que essa proteção acaba por destacar os produtos de uma determinada empresa, fidelizando os consumidores em detrimento dos concorrentes.

Buscar-se-á responder a alguns questionamentos relacionados à exploração de desenhos industriais, tais como: Seriam válidos esses registros individuais de peças, à luz dos requisitos da novidade e originalidade? Poderiam os titulares de desenhos industriais alegar proteção de seus produtos, no que diz respeito a qualidade e procedência? Os registros de desenhos industriais de partes de produtos podem caracterizar-se como uma monopolização de mercado aos seus titulares em detrimento dos concorrentes? Há abusividade por parte de titulares de desenhos industriais de peças separadas de bens? Seria possível a concessão de licenças em caráter compulsório para a exploração de desenhos industriais?

A presente pesquisa buscará desenvolver o tema, analisando para tanto as regras pertinentes ao registro do desenho industrial, à concorrência desleal e as vantagens dessa proteção para a pessoa jurídica, a fim de analisar ao final se tais proteções são pertinentes e valorizam a atividade econômica e o crescimento empresarial.

Será utilizado como método de pesquisa o indutivo, a saber, aquele destinado a verificar constatações particulares, e possibilitar, que se produzam generalizações sobre o tema. Os procedimentos metodológicos a serem utilizados serão o estudo dogmático jurídico, visto a impossibilidade de um estudo profundo sem que se recorra à lei, à doutrina ou à jurisprudência neste sentido; e o estudo sistemático, visando interpretar as regras específicas da pesquisa em harmonia com todo o sistema jurídico.

\section{1 - Aspectos gerais dos desenhos industriais.}


O conceito legal de desenho industrial encontra-se destacado no artigo 95, primeira parte, da Lei 9.279/96, como sendo a forma plástica ornamental de um objeto ou o conjunto ornamental de linhas e cores que possa ser aplicado a um produto.

Deste conceito é possível perceber que existem duas espécies desse bem da propriedade industrial, uma ligada a forma dos objetos e outra ligada ao conjunto ornamental de linhas e cores em determinados produtos. A primeira modalidade é aquela que merece maior destaque, pois dá materialidade a determinados produtos, tal como os formatos de garrafas de refrigerantes, vidros de perfume, modelos e peças de veículos, dentre outros.

Sua exploração está intimamente relacionada aos aspectos estéticos que os produtos são apresentados para os consumidores, sendo inclusive essa a função esperada pelo seu titular, ou seja, a de "dotar a mercadoria produzida de um elemento ornamental (nela mesma ou na embalagem) que a individualize no mercado, em relação aos concorrentes”. (COELHO, 2012, p. 210).

Esse aspecto visual que o desenho industrial proporciona não implica em melhoria de função nos produtos ou serviços oferecidos pelos seus titulares, entretanto, constitui atrativo visual e estético capaz de chamar a atenção e a preferência da clientela em geral. ${ }^{3}$ Essa característica inclusive remonta à segunda parte do art. 95 da Lei 9.279/96, a qual indica que os requisitos para que os desenhos industriais sejam merecedores de registro são a novidade e a originalidade. ${ }^{4}$

Por novidade compreende-se a forma nova que o objeto se apresenta em relação aos demais, devendo ser apresentado a registro sem que tenha sido divulgado ao público, dentro ou fora do país. Mesmo que o objeto não seja novo, deve apresentar combinações ou disposições novas de elementos conhecidos.

Já a originalidade está associada aos critérios técnicos que os classificam como criações intelectuais, diferenciando-os de outros bens que já existem, públicos ou privados. “Tudo está na maneira pessoal de tratar o assunto, imprimindo o autor à sua criação um cunho

\footnotetext{
${ }^{3}$ Newton SILVEIRA destaca que os desenhos industriais não devem ser acompanhados de uma função técnica, hipótese que lhes caracterizaria como modelo de utilidade: "Tal forma, entretanto, deve achar-se desvinculada da função técnica, isto é, não pode constituir em uma forma necessária para que o produto preencha a sua finalidade, hipótese em que se configuraria um modelo de utilidade.” (2014, p. 7).

${ }^{4}$ Parte final do art. 95 da Lei 9.279/96: "proporcionando resultado visual novo e original na sua configuração externa e que possa servir de tipo de fabricação industrial."
} 
novo, uma individualidade própria, que a distinga de outras semelhantes" (CERQUEIRA, 1982, p. 663).

O desenho industrial está associado a um direito que protege a aparência dos produtos, seja na sua totalidade ou parte, de modo a torna-lo mais desejável aos consumidores. Isso ocorre porque o que se destaca é a imagem que a clientela faz de tudo aquilo que lhe é oferecido, servindo como verdadeiro instrumento de sucesso da atividade empresária, na medida em que os consumidores se sentem satisfeitos não apenas por adquirir um produto, mas pela forma como ele se apresenta.

Nesse sentido destaca Clark (1966, p. 218):

Conquanto a teoria trate a diferenciação do produto como caso especial, ela é, na verdade, a mais geral, ou a classe mais extensa, uma vez que, praticamente, todos os produtos e serviços na indústria e comércio envolvem alguma diferenciação entre os vendedores concorrentes, nos próprios produtos, nos serviços a eles ligados, incluindo o transporte, ou na "imagem" que se forma na mente do comprador. Seguese daí que a maioria dos defeitos da concorrência, e não menos a maioria de suas virtudes, é encontrada em concorrência desse tipo.

Exemplo simples que pode ilustrar a predileção de consumidores por determinadas formas está na venda de veículos, cujo aspecto estético do produto destaca-se como um dos principais critérios para a escolha dos compradores, dentre os diversos modelos em oferta no mercado oferecidos por montadoras concorrentes ${ }^{5}$.

Os desenhos industriais aparecem, portanto, como elementos estéticos supérfluos que em nada alteram a utilidade dos objetos, mas que refletem um gosto específico da clientela, fidelizando assim os consumidores através de aspectos ornamentais. ${ }^{6}$

Além da estética, a utilidade também é um critério importante relacionado a esse bem da Propriedade Industrial, cujo formato pode conferir mais conforto aos consumidores, tal como ocorrem nos itens de vestuário. "Como se verifica, o desenho industrial compõe dois

\footnotetext{
${ }^{5}$ Nesse sentido ver pesquisa divulgada por GROHMANN, Marcia Zampieri e SCHAEDLER, Andréia Regina. O comportamento do consumidor de automóveis: fatores importantes para a decisão de compra. Disponível em http://www.abepro.org.br/biblioteca/enegep2007_tr610456_9111.pdf. Acesso em 15 de agosto de 2016.

${ }^{6}$ Sobre o caráter acessório e supérfluo dos desenhos industriais destaca João da Gama CERQUEIRA: "Não é o fato de se poder suprimir do objeto o desenho que o adorna, sem prejudicar lhe a serventia, que demonstra o caráter acessório do desenho, mas o fato de ser dispensável ou supérflua a ornamentação do objeto para o fim a que ele se destina. (1982, p. 678).
} 
elementos que no mundo moderno não mais se contrapõem: a funcionalidade e a estética" (SILVEIRA, 2007, p. 279)

Essa interação entre estética e utilidade também foi destacada por Ascarelli (1970, p. 615):

Cerâmicas, lustres, tapeçarias, utensílios, gravatas, sapatos ou criações da moda, constituem objeto de uso, mas objetos a respeito dos quais a forma pode apresentar, além de um alcance funcional, um alcance estético e, muitas vezes, somente este.

Justamente, por apresentar esse aspecto estético associado a um alcance funcional é que os desenho industriais já foram associados a invenções, guardando semelhanças entre seu procedimento de registro e as patentes, entretanto, é importante esclarecer que as criações ornamentais aparecem como elementos acessórios de produtos industriais, sem revestir-se do caráter de inovação tecnológica. É o que se destaca na posição de Barbosa (2013, p. 392): “ainda que o modelo da proteção dos desenhos industriais siga, como razoável similitude, o das patentes, não o podermos, na verdade, classificar como de 'proteção às tecnologias"”.

Deste modo, entende-se que o universo criativo é o principal motivador dos desenho industriais, cuja exploração está relacionada a concessão de registro perante o Instituto Nacional da Propriedade Industrial, por um período de 10 anos, prorrogados por mais 5 anos por três vezes, em que seu titular poderá excluir terceiros não autorizados de produzir, usar, colocar a venda, vender ou importar os objetos protegidos.

Após a extinção o desenho industrial cai em domínio público, podendo, somente a partir daí, vir a ser utilizado por qualquer interessado, sem autorizações prévias ou licenças.

\section{2 - Implicação da exploração dos desenhos industriais no universo da concorrência.}

Conforme mencionado anteriormente a aplicação prática de desenhos industriais está relacionada as formas plásticas ornamentais aplicadas aos produtos propriamente ditos e o conjunto ornamental de cores e linhas aplicada a um determinado produto. Em ambas o titular recebe a mesma proteção jurídica, adquirida com o registro no INPI, a qual engloba tanto o direito de propriedade imaterial dessa forma distintiva de produtos, embalagens e conjuntos ornamentais, bem como o direito de exclusividade na sua exploração empresarial. 


\section{Implicação da exploração dos desenhos industriais no universo da concorrência}

Tal como ocorre com os demais bens da Propriedade Industrial, a exploração exclusiva conferida aos desenhos industriais constitui instrumento eficaz no combate a concorrência desleal, pois protege o empresário das práticas anticompetivivas de seus concorrentes, especialmente no que diz respeito a possibilidade de imitação do formato dos produtos que comercializa ou mesmo de suas embalagens.

Assim, sua violação não significa somente uma afronta aos direitos da Propriedade Industrial, mas também um ato de concorrência desleal, pois todo aquele que vender, importar, exportar, oferecer ou colocar à venda produtos que violem a exploração exclusiva desse bem incorpóreo de caráter ornamental estará desviando a atenção da clientela.

Nesse sentido o doutrinador português Luís M. Couto GONÇALVES (2012, p. 123) afirma: "o que importa mais não é a valoração estética do produto, mas sim a susceptibilidade de proporcionar sensação estética ao consumidor".

Importante destacar que o desvio de clientela não é a única forma reconhecida na doutrina como concorrência desleal, sendo apenas um dos casos previstos no artigo 195 da Lei 9.279/96, entretanto, quando analisado sob a ótica específica dos desenhos industriais é o principal elemento caracterizador dessa prática prejudicial ao mercado.

O violador do desenho industrial tem a nítida intenção de atrair os interesses dos consumidores para os produtos que coloca no mercado, especialmente pela semelhança ornamental dos mesmos com os produtos do titular do desenho industrial.

A cópia do formato de produtos de interesse dos consumidores, mesmo que parcialmente, acaba por conferir uma vantagem econômica ao concorrente violador o que o permite alcançar um sucesso econômico baseado na pesquisa e empenho daqueles detentores do registro do desenho industrial.

No tocante a violação parcial do desenho industrial, é bom salientar que a Lei 9.279/96, ao tratar dos crimes contra os desenhos industriais, nada mencionou a respeito da extensão da violação quanto a todo o conteúdo desse bem da Propriedade Industrial ou apenas parte dele. A solução para esse problema pode ser encontrada através de uma interpretação analógica em relação aos registros de marca, cuja violação pode se caracterizar pela reprodução no todo ou em parte, conforme destaca o inciso I do artigo 189 da Lei 9.279/96. ${ }^{7}$

\footnotetext{
7 Art. 189. Comete crime contra registro de marca quem:

I - reproduz, sem autorização do titular, no todo ou em parte, marca registrada, ou imita-a de modo que possa induzir confusão.
} 
Essa analogia é perfeitamente compatível, uma vez que tanto a marca quanto o desenho industrial são bens da Propriedade Industrial protegidos por registro, com funções semelhantes no sentido de destacar o produto ou serviço do empresário de seus concorrentes.

Para evitar tais violações, o titular do desenho industrial poderá utilizar-se de instrumentos processuais e administrativos a fim de garantir a exploração exclusiva de seus direitos, tais como: a apreensão administrativa que pode ser realizada de ofício por autoridades alfandegárias ou a requerimento do interessado; as medidas judiciais cautelares de busca e apreensão na ocorrência de crime; e as ações judiciais indenizatórias, buscando a reparação do prejudicado quanto ao dano emergente e o lucro cessante que a violação desse bem da Propriedade Industrial causou, bem como dos atos de concorrência.

Exemplo prático de tais ações pode ser extraído de julgado proferido pelo Tribunal de Justiça de Minas Gerais que divulgou notícia a respeito da condenação de empresas por violarem desenho industrial devidamente registrado, ensejando assim em prática de concorrência desleal:

Encerrando uma disputa judicial envolvendo modelos de calçados, uma decisão da

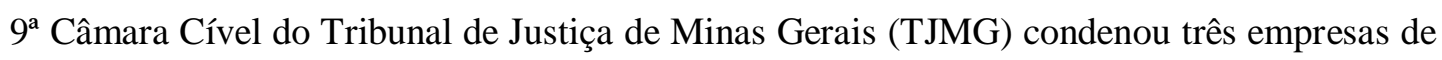
Juiz de Fora, na Zona da Mata mineira, a indenizar a Grendene S/A pela comercialização de produtos idênticos aos seus e a suspender a venda dos sapatos genéricos. A desobediência à determinação está sujeita a punição por multa diária de $\mathrm{R} \$ 300$.

A indenização, entretanto, deverá ser apurada em sentença por arbitramento. A quantia vai ser fixada levando-se em conta, dentre três possibilidades, a que mais beneficiar o prejudicado: os lucros que ela teria se a violação não tivesse ocorrido, os benefícios que a empresa que violou o direito teve ou a remuneração que a empresa violadora teria de pagar ao titular do direito pela concessão de licença para explorar o bem. ${ }^{8}$

Além do Tribunal Mineiro essa tendência é seguida por outros tribunais ${ }^{9}$ que veem na violação do desenho industrial uma prática de concorrência desleal, pacificando tal entendimento.

\footnotetext{
${ }^{8}$ Disponível em: http://tj-mg.jusbrasil.com.br/noticias/1936973/tj-pune-violacao-de-desenho-industrial.

${ }^{9}$ Veja-se o Exemplo de acórdão do Tribunal de Justiça do Rio Grande do Sul: APELAÇÃO CÍVEL. PROPRIEDADE INDUSTRIAL. AÇÃO ORDINÁRIA POR VIOLAÇÃO DE DESENHO INDUSTRIAL, CONCORRÊNCIA DESLEAL COMBINADA COM PERDAS E DANOS. REGISTRO DE DESENHO INDUSTRIAL. O presente feito trata de matéria referente ao direito de propriedade industrial/intelectual, sendo a matéria de competência de uma das Câmaras integrantes do $3^{\circ}$ Grupo Cível, nos termos do art. 11, III, h, da Resolução nº 1/98. COMPETÊNCIA DECLINADA. (Apelação Cível No 70040664237, Décima Sexta Câmara
} 


\section{Implicação da exploração dos desenhos industriais no universo da concorrência}

Por outro lado, questão polêmica que merece reflexão é a possibilidade do titular do desenho industrial utilizá-lo de forma abusiva em detrimento de seus concorrentes.

Tal hipótese não se mostra tão simples quanto a análise feita da utilização abusiva das marcas e das patentes, pois a característica ornamental e as possibilidades de caducidade do desenho industrial lhes conferem características próprias, despidas de conteúdo tecnológico e sujeitas ao domínio público posterior.

Problema prático atual vem se evidenciado na indústria de autopeças e veículos, em que algumas montadoras utilizam-se do desenho industrial não somente para garantir o direito de exploração exclusiva da estrutura básica dos veículos, mas também das peças que compõem os mesmos, tais como faróis, para-choques, espelhos retrovisores e outras.

Os registros de desenhos industriais das montadoras sobre as peças dos automóveis e não apenas ao modelo do veículo como um todo tem desagradado as empresas produtoras de autopeças, especialmente aquelas que trabalham com peças de reposição de veículos no mercado paralelo, pois o registro do design de algumas peças lhes impedem de produzi-las, salvo se obtiverem licença para tanto, limitando assim sua atuação empresarial e reduzindo seus lucros.

Esse descontentamento acabou por gerar a instauração do procedimento administrativo de Averiguação Preliminar n. 08012.000487/2000-40 junto ao CADE, promovido pela Federação Nacional de Distribuidores de Veículos Automotores FENABRAVE em desfavor de Volkswagen do Brasil S/A, General Motors do Brasil Ltda, Ford Motor Company Brasil Ltda., Fiat Automóveis S/A e Associação Nacional dos Fabricantes de Veículos - ANFAVEA. ${ }^{10}$

No referido procedimento, os julgadores entenderam pelo seu arquivamento para posteriores averiguações, face a grande complexidade da matéria, uma vez que a mesma envolve situações que pautam não apenas pelas relações de infração à ordem econômica, mas também à concorrência desleal e a Propriedade Industrial. ${ }^{11}$

Cível, Tribunal de Justiça do RS, Relator: Munira Hanna, Julgado em 29/08/2013) (TJ-RS Relator: Munira Hanna, Data de Julgamento: 29/08/2013, Décima Sexta Câmara Cível).

${ }^{10}$ Disponível em: http://www.cade.gov.br/Default.aspx?e15cb044c84cdd37c95ea276bc56d673c6. Acesso em 20 de outubro de 2014.

${ }^{11}$ Em trecho da decisão: O Relator, de um lado, votou pelo conhecimento do recurso, para determinar o arquivamento das presentes averiguações e de outro, diante do indício de práticas de cartel, por sugerir à SDE a promoção de novas averiguações preliminares, contra as mesmas averiguadas e a ANFAVEA, para apuração da ocorrência das infrações contra a ordem econômica previstas no artigo 21, incisos I e II, da Lei no. 8.884/94, tendo sugerido ainda a constituição de grupo de trabalho para avaliar possíveis medidas de desregulação do mercado de comercialização de veículos automotivos, com vistas a estimular práticas de livre mercado no setor. 
O primeiro questionamento apresentado quanto a essa temática circunscreveu-se na possibilidade ou não de registar separadamente as peças de um automóvel, ao invés da estética do veículo como um todo. Seriam válidos esses registros individuais de peças, à luz dos requisitos da novidade e originalidade?

Para o registro dos desenhos industriais é necessário comprovar a sua novidade e originalidade, ou seja, eles não podem estar incluídos no estado de técnica, que representa o conjunto de formas já conhecidas e exploradas, aliadas ao fato de que elas não podem ser vulgares ou comuns, representando um caráter artístico original na sua formação. A ausência desses requisitos impede o desenho industrial de receber a proteção jurídica de exploração exclusiva pelo INPI.

Segundo Gama Cerqueira (1982, p. 662):

(...) seria injusto conferir-se a qualquer pessoa um direito exclusivo sobre coisas que não resultam de seu trabalho e pertencem ao domínio público ou ao patrimônio comum das artes e das industrias. Não se requer, porém, que o desenho ou modelo seja inteiramente novo ou original, bastando que se distinga dos objetos comuns e de outros desenhos ou modelos conhecidos.

Desse modo, a regra a ser observada quanto as peças separadas de automóveis está no fato de considerar se ela é uma parte independente do modelo do veículo devidamente registrado como desenho industrial ou se sua conformação está a ele indissociada.

No Direito Português, o artigo 173 do Código da Propriedade Industrial soluciona essa questão permitindo o registro do todo ou parte de um produto como desenho industrial. ${ }^{12}$ Entretanto, Luís M. Couto Gonçalves (2012, p. 125) destaca que é necessário fazer uma interpretação restritiva dessa proteção, pois “deve tratar-se de formas parcelares integradas na forma global do desenho ou modelo. A protecção da aparência significa que a forma da totalidade ou de parte do produto deva ser exterior e visível".

Disponível em: http://www.cade.gov.br/Default.aspx?e15cb044c84cdd37c95ea276bc56d673c6. Acesso em 20 de outubro de 2014.

${ }^{12}$ Art. $173^{\circ}$. através do registro de marca com elementos conflitantes com registros anteriores, da concentração de marcas e da realização de contratos de exclusividade com fornecedores ou revendedores.

Disponível em: http://www.marcasepatentes.pt/files/collections/pt_PT/1/2/14/Decreto-

Lei\%20n.\%C2\%BA\%20143_2008\%20de\%2025\%20de\%20Julho_C\%C3\%B3digo\%20da\%20PI\%20-

\%20Vers\%C3\%A3o\%20pesquis\%C3\%A1 vel\%20em\%20PDF.pdf. Acesso em 20 de outubro de 2016. 


\section{Implicação da exploração dos desenhos industriais no universo da concorrência}

Portanto, sob a ótica dessa legislação estrangeira as peças de automóvel poderiam receber o registro de desenho industrial desde que se apresentem de forma individualizada, exteriores e visíveis.

No Direito pátrio, Fabio Ulhoa Coelho (2010) também concorda com a possibilidade do registro do desenho industrial de peças separadas de veículos, entretanto, em parecer apresentado ao processo 2010.51.01.809326-0, a cargo da 35 Vara Federal da Seção Judiciária do Rio de Janeiro, ofereceu outra solução ao caso, ligada aos aspectos econômicos da comercialização individual daquelas peças de automóvel:

O critério para se distinguir uma situação da outra é o da existência de mercado para essa parte componente. Se uma parte componente não for suscetível de comercialização em separado do produto que integra, então não é um “objeto” próprio, autônomo, independente, apto a suportar desenho industrial registrável. Mas havendo mercado para a comercialização desta parte componente, em separado do bem por assim dizer "principal", a proteção do respectivo desenho industrial se impõe quando atendidos os requisitos legais de sua concessão.

Outro ponto relevante em debate no caso específico das autopeças circunscreveu-se aos aspectos de funcionalidade do objeto do desenho industrial, cujo inciso II do artigo $100 \mathrm{da}$ Lei $9.279 / 96^{13}$ proíbe o registro das formas determinadas essencialmente por considerações técnicas ou funcionais.

A dúvida reside no fato de serem as peças instrumentos funcionais dos automóveis ou elementos independentes despidos dessa funcionalidade? Se comprovada a primeira hipótese elas não poderiam receberem proteção individual através do registro de desenho industrial. Ao contrário, poderiam receber o direito de exploração exclusiva se essa funcionalidade não interferisse na sua individualidade.

A solução dessa dúvida remete à mesma autonomia dos registros de partes de objetos anteriormente mencionada, pois que uma parte autônoma, exterior e visível, com um comércio próprio e independente, não poderia ser considerada de mero aspecto técnico ou funcional.

\footnotetext{
13 Art. 100. Não é registrável como desenho industrial:

I - o que for contrário à moral e aos bons costumes ou que ofenda a honra ou imagem de pessoas, ou atente contra liberdade de consciência, crença, culto religioso ou ideia e sentimentos dignos de respeito e veneração;

II - a forma necessária comum ou vulgar do objeto ou, ainda, aquela determinada essencialmente por considerações técnicas ou funcionais.
} 
Em outro parecer sobre a matéria, José Roberto d'Affonseca Gusmão (2010) manifesta no sentido de não haver impedimento no registro de peças exteriores de automóveis, mesmo que a funcionalidade esteja presente, desde que ela não seja predominante:

Reitera-se, mais uma vez, que a forma funcional pode estar presente no desenho industrial. Veda-se o registro, apenas, se ela for predominante. Nesse contexto, vale reportar as observações de Frederico Carlos da Cunha, no sentido de que "a maioria dos objetos do design é desenvolvida para exercer alguma função prática, e as formas consideradas funcionais podem revelar também características ornamentais". Logo, muito embora tenha caráter funcional, o desenho industrial será registrável se a forma ornamental do objeto reivindicado não for determinada, de maneira predominante, por essa função.

Constata-se que peças separadas de veículos ou de outros utensílios, tais como liquidificadores, bicicletas, aparelhos tecnológicos, podem receber o certificado de registro do INPI desde que atendam aos requisitos legais e se mostrem suficientemente individualizados e exteriores.

Não está evidenciado que a utilização do registro de desenhos industriais de partes de produtos possa ser considerado um ato abusivo de seus titulares, ao contrário, representa o exercício regular do direito daqueles que investem nos aspectos diferenciadores de seus produtos em busca de uma clientela.

Esse inclusive foi o entendimento do Tribunal Regional Federal da $2^{\mathrm{a}}$ Região no julgamento do processo 2010.51.01.809326-0:

EMENTA APELAÇÃO CÍVEL. PROPRIEDADE INDUSTRIAL. DESENHO INDUSTRIAL. REGISTRO. NULIDADE. PEÇAS DE AUTOMÓVEL. LEI 9279/96. REQUISITOS. POSSIBILIDADE. CONCORRÊNCIA DESLEAL. 1- Na forma do art. 95 da Lei $n^{\circ}$ 9279/96, para que haja proteção do desenho industrial, o objeto ou o padrão gráfico deve apresentar um resultado visual novo, original e ter utilização industrial, não havendo na Lei de Propriedade Industrial qualquer restrição que proíba o registro das peças automotivas em si, nem tampouco o registro de partes de objetos como desenho industrial. 2-As peças de automóvel, embora possuam sua forma considerada técnica ou funcional, para atender às necessidades impostas à fabricação do veículo, também podem possuir características ornamentais diferenciadas, com visuais próprios, de acordo com o design utilizado no modelo de cada automóvel, sendo passível seu registro como desenho industrial, não 


\section{Implicação da exploração dos desenhos industriais no universo da concorrência}

havendo que se falar em violação ao disposto no art. 100, inciso II da LPI. 3-A ideia de que a concessão de um registro de desenho industrial gera monopólio de mercado e concorrência desleal, pelo que deve ser declarado nulo, vai de encontro à lógica do sistema de propriedade industrial, segundo a qual, em razão do benefício que o invento/criação do particular trouxe a toda a sociedade, esta, por um tempo determinado, lhe concederá um privilégio para exploração e utilização exclusiva da invenção/criação, a fim de que possa ser recompensado e, assim, continuar investindo em inovação, contribuindo para o interesse social e para o desenvolvimento tecnológico do país. 4- Recursos de apelação e remessa necessária providos. ${ }^{14}$

Atitude abusiva praticam as empresas que se utilizam da produção desses bens protegidos, sem qualquer critério de qualidade auferido pelas montadoras, colocando no mercado produtos que em muitos casos são tecnicamente inferiores aos originais, cuja consequência negativa da repulsa do consumidor será sofrida não pelas empresas de autopeças, mas por aqueles que comercializam o produto como um todo.

Desse modo, conclui-se que a exploração de desenhos industriais não configura ato abusivo por seus titulares quando seu registro estiver sendo utilizado para proteção de partes de objetos, desde que externos, visíveis e passíveis de alienação individual.

Do mesmo modo as demais situações abusivas anteriormente destacadas nos casos de patentes e marcas, igualmente não poderiam ser aplicadas aos desenhos industriais, quais sejam: a concentração e a falta de uso efetivo por seu titular.

Na primeira hipótese, essa impossibilidade se explica pelo fato de que o empresário poderá criar tantos desenhos quantos forem aqueles que atendam aos critérios de originalidade e novidade, utilizando-os para ornamentar seus produtos, embalagens ou disposição de linhas e cores.

Mesmo que o empresário retenha esses direitos sem a devida utilização, tal como nas marcas, o registro poderá ser extinto através do procedimento de nulidade, que irá correr de forma administrativa junto ao INPI ou através de ação própria perante a Justiça Federal.

\footnotetext{
${ }^{14}$ Disponível em:

http://jurisprudencia.trf2.jus.br/v1/search?q=cache:_GAVyDNPdvoJ:trf2nas.trf.net/iteor/TXT/RJ0108210/1/113/ 468760.rtf+2010.51.01.809326-

$0+\&$ client=jurisprudencia\&output=xml_no_dtd\&proxystylesheet=jurisprudencia\&lr=lang_pt\&ie=UTF-

$8 \&$ site $=$ acordao \&access $=$ p\&oe $=U T F-8$. Acesso em 20 de agosto de 2014.
} 
Importante lembrar que a Lei da Propriedade Industrial não apresentou uma hipótese de extinção do registro do desenho industrial por falta de uso, passando essa análise hermenêutica pela observância do disposto no inciso II do art. 119 que permite a extinção do registro pela renúncia do titular. ${ }^{15}$

A renúncia do titular do desenho industrial pode ser comprovada justamente pela falta de utilização econômica, pois o direito de exploração que lhe foi conferido em caráter de exclusividade não se visualiza na prática, tornando, portanto, descabida a necessidade de uma tutela específica.

Uma vez extinto, “o desenho industrial cai em domínio púbico, podendo, a partir de então, vir a ser utilizado por qualquer pessoa interessada, sem qualquer pagamento de licença ou autorização do antigo detentor de direitos de exclusividade". (NEGRÃO, 2012, p. 167)

Outra hipótese que não poderia ser considerada ato abusivo da exploração do desenho industrial seria a recusa de licenciamento, uma vez que sua exploração não está associada a inovação tecnológica.

O licenciamento representa uma proximidade do desenho industrial com as invenções e modelos de utilidade, cujo revogado Decreto-Lei 7.903 conferia a todos proteção específica através de cartas patentes, com procedimento de concessão bastante parecido.

Também a exploração do desenho industrial por terceiros não titulares do registro deverá ser feita através de contratos de licença voluntária que serão devidamente averbados no INPI, em conformidade com o artigo 61 e 62 da Lei 9.279/96. ${ }^{16}$

Entretanto, ao contrário do que ocorre com as patentes, o desenho industrial não se reveste de uma inovação tecnológica, que poderia servir para acalentar problemas sociais ou promover o desenvolvimento de países. Repita-se que o desenho

15 Art. 119. O registro extingue-se:

I - pela expiração do prazo de vigência;

II - pela renúncia de seu titular, ressalvado o direito de terceiros;

III - pela falta de pagamento da retribuição prevista nos arts. 108 e 120; ou

IV - pela inobservância do disposto no art. 217.

${ }^{16}$ Art. 61. O titular de patente ou o depositante poderá celebrar contrato de licença para exploração.

Parágrafo único. O licenciado poderá ser investido pelo titular de todos os poderes para agir em defesa da patente.

Art. 62. O contrato de licença deverá ser averbado no INPI para que produza efeitos em relação a terceiros.

$\S 1^{\circ} \mathrm{A}$ averbação produzirá efeitos em relação a terceiros a partir da data de sua publicação.

$\S 2^{\circ}$ Para efeito de validade de prova de uso, o contrato de licença não precisará estar averbado no INPI. 
industrial reveste-se, de uma característica de futilidade que o aproxima das obras de arte. Nesse sentido Newton Silveira (2014, p. 279-280) destaca seu caráter estético:

O design representa a união entre a técnica e a estética, fenômeno do sistema industrial moderno que não pode ser reduzido aos critérios convencionais da arte e da técnica. As novas criações de forma devem, assim, acompanhar a evolução da matéria e ser disciplinadas sem dependência das categorias rígidas da técnica e da estética. Tal forma é fruto da atividade criativa do designer e pode ser considerada como integrante da estética contemporânea.

Portanto, não é possível falar-se em concessão obrigatória de licenças de uso, especialmente pelo fato de que essa concessão está adstrita à vontade do titular do desenho industrial. Não existem medidas coercitivas que lhe imputem a obrigação de contratar com outros empresários o direito de exploração do desenho industrial.

Com isso conclui-se que no caso dos desenhos industriais, dificilmente poderia ser detectada uma hipótese em que sua utilização pudesse ser caracterizada como abusiva, justamente pelo fato de se revestir desses critérios artísticos e fúteis. Mais comum se mostra a figura do desenho industrial como vítima de atos de concorrência e não como algoz.

\section{CONCLUSÃO}

De todo o exposto, podemos concluir ao final que a exploração de qualquer bem da propriedade industrial, por mais que tenha regras definidas, ainda assim apresenta-se de forma complexa, justamente pelas inovações de formas, símbolos e tecnologias que surgem diuturnamente.

Dentre esses bens, o presente artigo buscou enfatizar a exploração dos desenhos industriais como bens da propriedade industrial relacionados a aspectos estéticos, quais sejam formas plásticas ornamentais e o conjunto ornamental de cores e linhas aplicadas aos produtos comercializados.

A exploração do desenho industrial proporciona atrativo visual e estético capaz de chamar a atenção e a preferência da clientela em geral, desse modo fomentando a concorrência e o interesse de diversos empresários. Nesse sentido foi esclarecido que para a 
proteção específica de desenho industrial que demonstre originalidade e novidade é necessário registro próprio junto ao Instituto Nacional da Propriedade Industrial.

Restou demonstrado que esta proteção exclusiva conferida aos desenhos industriais constitui instrumento eficaz no combate a concorrência desleal, pois protege o empresário de práticas anticompetivivas.

Ainda, percebe-se que o registro de bens ou de partes independentes de objetos, em regra, não são utilizados de forma abusiva nos casos práticos destacados, respondendo aos questionamentos iniciais.

Os questionamentos iniciais foram respondidos demonstrando que são válidos os registros individuais de peças isoladas, desde que com comércio específico, à luz dos requisitos da novidade e originalidade. Ainda que os titulares de desenhos industriais podem alegar proteção de seus produtos, no que diz respeito a qualidade e procedência para evitar a concessão de licenças, não caracterizando uma monopolização de mercado em detrimento dos concorrentes, uma vez que esses bens caem em domínio público, não sendo comprovada abusividade.

Por fim, restou demonstrado que essa proteção destaca os produtos de uma determinada empresa, no sentido de buscar fidelizar seus consumidores em detrimento de seus concorrentes, não se posicionando o empresário como praticante de ato de concorrência desleal, mas sim o contrário, muitas vezes, como vítima.

\section{BIBLIOGRAFIA}

ASCARELLI, Tullio. Teoría de la Concurrencia y de los Bienes Inmateriales. 3 ed. Barcelona: Bosch, 1970.

CERQUEIRA, João da Gama. Tratado da Propriedade industrial. 2 ed. v.2. São Paulo: Revista dos Tribunais, 1982.

COELHO, Fábio Ulhoa. Curso de Direito Comercial. Direito de empresa. Empresa e estabelecimento. 16 ed. v. 1. São Paulo: Saraiva, 2012.

COELHO, Fábio Ulhoa. Jurisdição: Parecer. 2010.51.01.809326-0, a cargo da $35^{\text {a }}$ Vara Federal da Seção Judiciária do Rio de Janeiro. 2010

COPETTI, Michele. Registro de Marcas - Propulsor para o Desenvolvimento? In BARRAL W e PIMENTEL, L.O. Propriedade Intelectual e Desenvolvimento. Florianópolis: Boiteux, 2007.

CLARK, John Maurice. A Concorrência como processo dinâmico. Tradução de JUNGMANN, Ruy. Rio de Janeiro: Editora Forense, 1966. 
FALCONI, Bruno. Propriedade Industrial e Defesa da Concorrência. Convergência Principiológica. Curitiba: Juruá,2013.

GONÇALVES Luís M. Couto. Manual de Direito Industrial. Propriedade Industrial e Concorrência Desleal. 3 ed. Coimbra: Almedina, 2012.

GROHMANN, Marcia Zampieri e SCHAEDLER, Andréia Regina. O comportamento do consumidor de automóveis: fatores importantes para a decisão de compra. Disponível em http://www.abepro.org.br/biblioteca/enegep2007_tr610456_9111.pdf. Acesso em 15 de agosto de 2016.

GUSMÃO, José Roberto d' Affonseca. Jurisdição: Parecer. 2010.51.01.809326-0, a cargo da $35^{\text {a }}$ Vara Federal da Seção Judiciária do Rio de Janeiro. 2010

NEGRÃO, Ricardo. Manual de Direito Comercial \& de Empresa. Teoria Geral da Empresa e Direito Societário. 9 ed. v. 1 São Paulo: Saraiva, 2012.

SILVEIRA, Newton. Propriedade Intelectual. Propriedade Industrial, Direito de Autor, Software, Cultivares, nome empresarial, abuso de patentes. 5ed. Barueri/SP: Manole, 2014. Os requisites de novidade e originalidade para a proteção do desenho industrial. in SANTOS, Manoel J. Pereira dos e JABUR, Wilson Pinheiro (coord.). Criações Industriais, Segredos de Negócio e Concorrência Desleal. São Paulo Saraiva, 2007. 